\section{Estudo \\ CoDebate}

em Testão

Planejamento
Revista Estudo \& Debate, Lajeado, v. 23, n. 2, 2016. ISSN 1983-036X

DOI: http://dx.doi.org/10.22410/issn.1983-036X.v23i2a2016.1071

\title{
ANÁLISE DO IMPACTO DOS TIPOS DE REVESTIMENTOS DO SOLO NA VARIAÇÁO DA TEMPERATURA NA CIDADE DE CUIABÁ
}

\author{
Kaira Cristina de Macedo ${ }^{1}$, Mariza de Mello Arruda Sampaio², Allyf Kumakura Alves ${ }^{3}$, \\ Andressa Tainara Campelo de Jesus ${ }^{4}$
}

\begin{abstract}
Resumo: Os processos de urbanizaçáo alteram, muitas vezes de forma negativa, o meio ambiente. Sendo o desconforto térmico gerado uma das principais consequências do uso e ocupação inadequado do solo, esta pesquisa visou estudar a relação entre a variação dos tipos de revestimentos do solo de uma região e a variação de temperatura registrada. Analisou-se quatro pontos da cidade de Cuiabá-MT entre os anos de 2003/2004 e 2013/2014, e verificou-se que os pontos onde houve um aumento da área arbórea teve diminuiçáo de temperatura média anual, com isso pode-se concluir que a arborização da cidade afeta positivamente o conforto térmico nela experimentado.
\end{abstract}

Palavras-chave: Conforto térmico. Revestimento do Solo. Arborização Urbana.

\section{ANALYSIS OF THE IMPACT OF DIFFERENT LANDCOVER MATERIALS ON THE VARIATION OF TEMPERATURE IN THE CITY OF CUIABÁ}

Abstract: Many times, the processes of urbanization change the environment in a negative way, and one of the main consequences of the inappropriate use and occupation of the soil is the thermal discomfort. The purpose of this research was to analyze the relationship between the variation of different soil cover in a specific region

1 Estudante de Engenharia Civil, Aluna no programa de Iniciaçấo Científica na Universidade Federal de Mato Grosso, na área de Conforto Ambiental.

2 Professora da UFMT, atuando na área de Projeto e Representação Gráfica, possui graduação em Arquitetura e Urbanismo pela Universidade Federal de Mato Grosso (2003), mestrado em Física Ambiental pela Universidade Federal de Mato Grosso (2006) e doutorado em Urbanismo pelo PROUrb/ Universidade Federal do Rio de Janeiro (2015).

3 Estudante de Engenharia Civil, Aluno no programa de Iniciação Científica na Universidade Federal de Mato Grosso, na área de Conforto Ambiental.

4 Estudante de Engenharia Civil, Aluna no programa de Iniciação Científica na Universidade Federal de Mato Grosso, na área de Conforto Ambiental. 
and the variation of temperature recorded. Four spots were analyzed in the city of Cuiabá MT, from 2003 to 2004 and from 2013 to 2014, as a result, it was verified that the places where there was an increase on green areas, the average of annual temperature decreased. It can be concluded that green areas affect positively the thermal comfort experienced in the city.

Keywords: Thermal comfort. Land Cover. Urban afforestation.

\section{INTRODUÇÁO}

O crescimento acelerado das cidades vem chamando a atenção para os problemas gerados pelas atividades humanas que, juntamente com a falta de mecanismos eficientes de controle, provocam diversos impactos ambientais. Tal situaçáo se reflete de maneira direta na qualidade de vida da população (SAMPAIO, 2015).

Segundo Gomes e Amorim (2003), a forma como acontece o uso e a ocupaçâo do solo relacionada à disposição do relevo pode gerar significativas alteraçóes no campo térmico urbano. Para eles, a intensificação da ação antrópica na constituição do meio urbano sem o devido planejamento acarreta problemas ambientais de várias dimensóes. Sobre as cidades, instala-se o fenômeno denominado "ilha de calor", que se caracteriza pelo aumento da temperatura do ar, devido à morfologia urbana, às propriedades térmicas dos materiais de revestimento do solo e dos edifícios e à ausência de áreas verdes, alterando o balanço da radiação nas áreas urbanas (SILVEIRA; ROMERO, 2005).

Silveira e Romero (2005) destacam ainda que, a absorção da radiação solar nas áreas urbanas, além de depender das fachadas e de seu arranjo geométrico, depende do albedo dos diferentes tipos de revestimento do solo e materiais urbanos, pois, a radiação solar absorvida aquece as superfícies que passam a emitir radiação de ondas longas, em funçáo da emissividade do material que constitui a superfície, aumentando a temperatura do ar.

Para Villar Filho, Araújo e Costa (2013), por mais que possam parecer pequenas as diferenças entre os materiais, estes no conjunto de superfícies totais podem gerar condiçóes microclimáticas e condiçôes de conforto térmico dos usuários bastante diferentes, devido à grande área da superfície.

O estudo da climatologia urbana é essencial para um efetivo planejamento dos municípios, independente do porte destes, já que atualmente diversos estudos científicos tem comprovado a existência de ilhas de calor em cidades de diferentes densidades (SOUZA; NERY, 2012).

É nesse contexto que se destaca a importância do estudo do impacto dos revestimentos no clima das cidades, visto que a urbanização gera alteraçôes do meio natural, principalmente no que diz respeito aos tipos de revestimento dos locais. Afim de analisar este impacto quanto ao conforto térmico da cidade, esta pesquisa estudou a variaçáo de temperatura e a variação dos tipos de revestimentos do solo de alguns pontos da cidade de Cuiabá-MT, nos anos de 2003/2004 e 2013/2014 com o objetivo de verificar como a mudança de revestimento do solo influenciou na variaçáo da temperatura da regiáo. 


\section{LOCAL DE ESTUDO}

Conhecida como uma das capitais mais quentes do Brasil, a cidade de Cuiabá localizada na porção Centro-Sul do Estado de Mato Grosso, na região denominada depressão cuiabana, foi escolhida para abrigar a pesquisa.

O município conta com uma extensão territorial de, aproximadamente, $3000 \mathrm{Km}^{2}$, estando situado no Centro Geodésico da América do Sul, nas coordenadas geográficas de $15^{\circ} 35^{\prime} 56^{\prime \prime}$ de latitude sul e 56 06'01" de longitude oeste, à altitude de 177 metros (CUIABÁ, 2009). Possui clima Tropical semiúmido, com quatro a cinco meses secos (junho a setembro) e máximas diárias de temperatura que oscilam entre $30^{\circ} \mathrm{C} \mathrm{e} 36^{\circ} \mathrm{C}$, apresentando duas estaçóes bem definidas, uma seca e uma chuvosa (SAMPAIO, 2015).

\section{MATERIAIS E MÉTODOS}

\subsection{Base de Dados de Temperatura}

Os dados de temperatura foram retirados da tese de doutorado "Transformaçóes climáticas e legislação: o caso de Cuiabá-MT” submetida ao Programa de Pós-Graduação em Urbanismo (PROURB), Faculdade de Arquitetura e Urbanismo (FAU), Universidade Federal do Rio de Janeiro (UFRJ), pela Msc. Mariza de Mello Arruda Sampaio como parte do requisito necessário à obtenção de seu título de doutora no ano de 2015 .

Em seu estudo, Sampaio (2015) montou um banco de dados de temperaturas com dados relativos aos anos de 2003/2004 e 2013/2014. Os dados de 2003/2004 foram coletados em trabalho realizado pela equipe do Grupo de Pesquisas em Geografia da Universidade Federal de Mato Grosso, enquanto que os dados de 2013/2014 foram coletados pela própria pesquisadora. $\mathrm{O}$ banco de dados criado é composto por quatorze pontos, localizados em diferentes configuraçóes de uso e ocupação do solo espalhados pela cidade de Cuiabá como mostra a Figura 1, sendo que, cada ponto estudado possui registros de mediçóes de temperatura as $8 \mathrm{hrs}$, as $14 \mathrm{hrs}$ e as $20 \mathrm{hrs}$, em três dias de cada mês, a partir dos quais Sampaio (2015) calculou as médias de temperatura mensais e anuais. 
Figura 1: Mapa contendo a localização dos pontos onde foram coletados dados de temperatura na cidade Cuiabá-MT

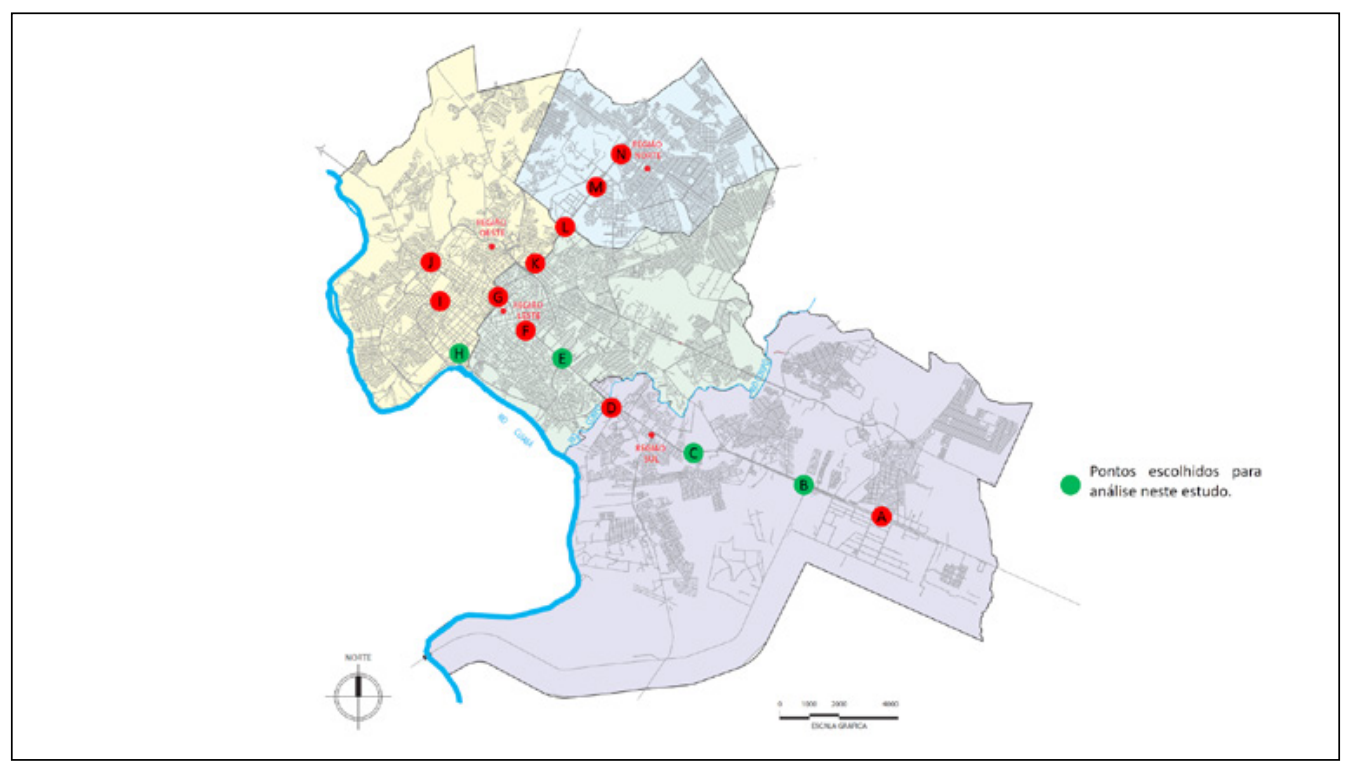

Fonte: dos autores.

\subsection{Materiais}

Foram escolhidos quatro pontos (FIGURA 1) dentre os quatorze pontos estudados por Sampaio (2015). Como critério de escolha usou-se a variação de temperatura média anual entre os anos de 2003/2004 e 2013/2014. Os pontos B e C foram escolhidos pois apresentaram as maiores diminuiçóes de temperatura anuais, e os pontos $\mathrm{E} \mathrm{e} \mathrm{H}$ pois apresentaram as maiores altas. Depois da escolha dos pontos, construiu-se uma base de dados com imagens aéreas conforme metodologia aplicada por Franco (2013). Para cada ponto foram escolhidas duas imagens do banco de dados do programa Google Earth, uma para o ano de 2003/04 e outra para o ano de 2013/14, compreendendo um raio de 200 metros do local onde foram coletados os dados de temperatura.

\subsection{Métodos}

A partir das imagens coletadas, com o auxílio do programa AutoCad, foi feito a caracterização e quantificação dos revestimentos em cada ponto, em cada ano, ou seja, a área coberta por cada tipo de revestimento nos anos de 2003/2004 e nos anos de 2013/2014 devido à baixa qualidade das imagens disponíveis a cobertura do solo foi classificada como arborizada, com grama, solo exposto, área construída e área asfaltada.

As figuras abaixo exemplificam essa parte do trabalho. Primeiro temos as imagens aéreas do ponto $\mathrm{B}$ (FIGURAS 2 e 3 ), e em seguida a imagem com os tipos de revestimentos do ponto B devidamente classificados (FIGURA 4). 
Figura 2: Ponto B - Registro de 2004

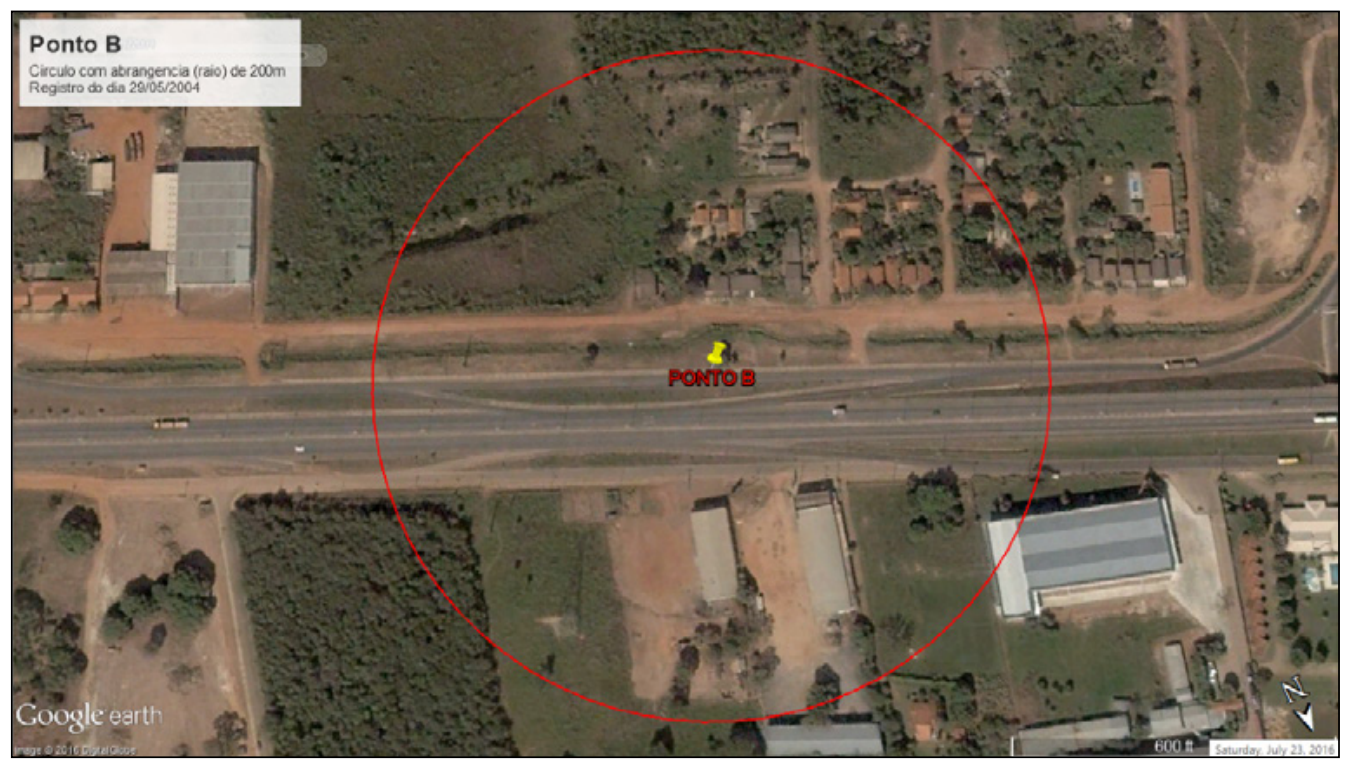

Fonte: Google Earth.

Figura 3: Ponto B - Registro de 2014

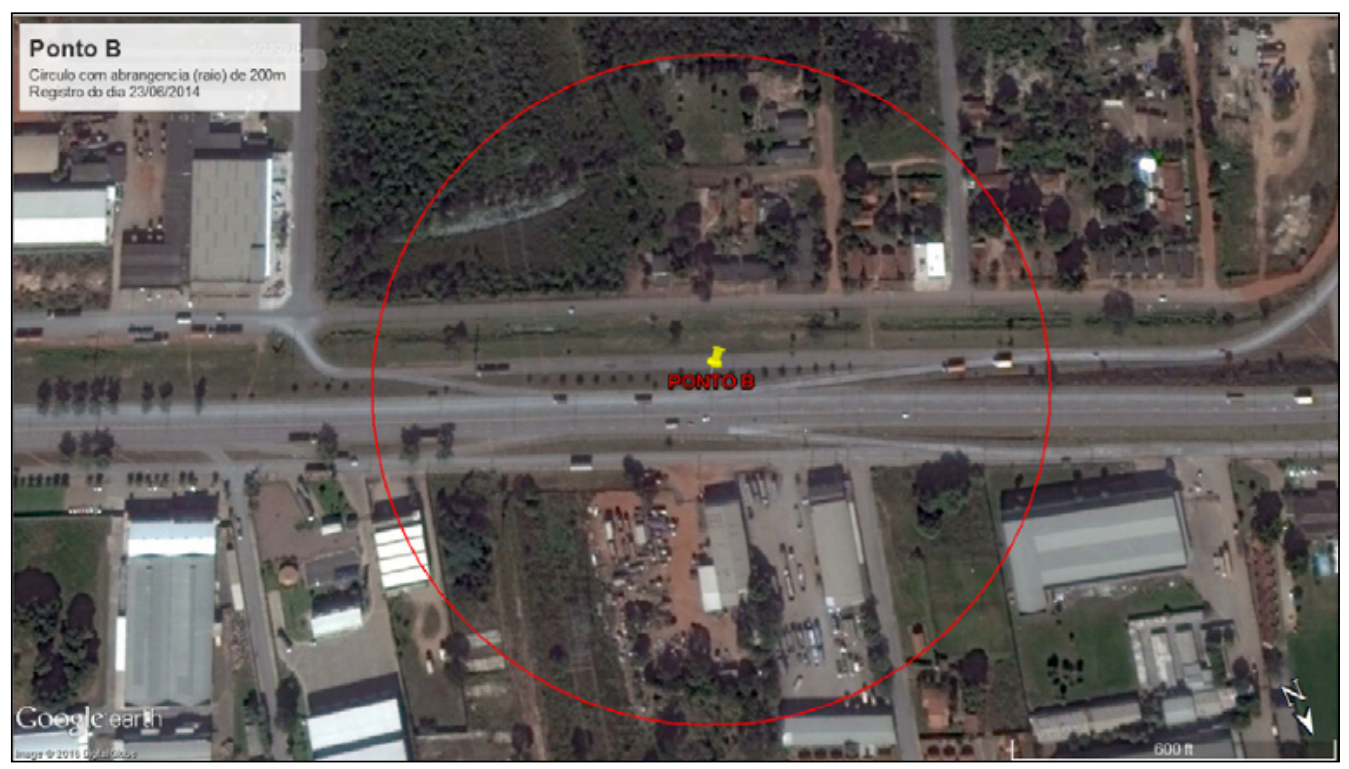

Fonte: Google Earth. 
Figura 4: Caracterização dos revestimentos do ponto B

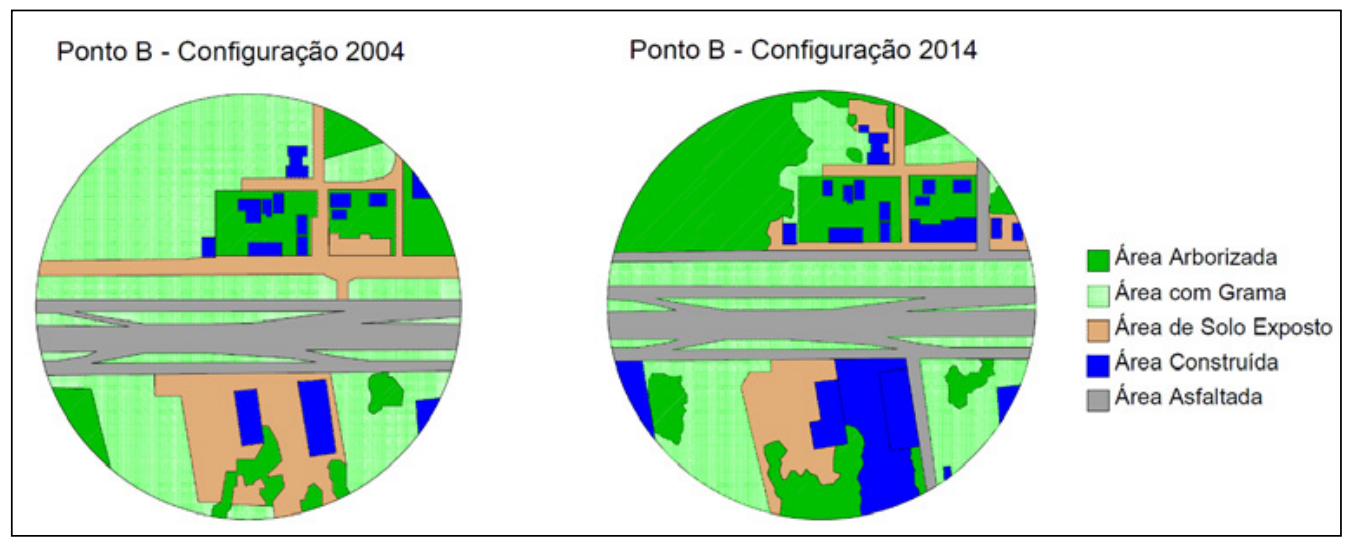

Fonte: dos autores.

Em seguida foi calculado em porcentagem (\%) o quanto a área coberta por cada revestimento variou, e também se calculou a variação da temperatura média anual entre os anos pesquisados. Com os dados de variação obtidos montou-se gráficos de barra, para uma melhor visualização da relação entre a variação dos revestimentos e da temperatura.

\section{ANÁLISE DE RESULTADOS POR PONTO}

\subsection{Ponto B}

O ponto B foi localizado na Avenida Fernando Corrêa da Costa no Distrito Industrial da cidade Cuiabá, antes do acesso à Rodovia dos Imigrantes. O uso e ocupaçáo do solo da região é caracterizado por áreas verdes de fazendas limítrofes à rodovia, algumas indústrias, pouco comércio e pouca moradia. Ele foi escolhido pois, dentre os pontos estudados, foi o que apresentou a maior diminuiçáo de temperatura média anual em 10 anos, cerca de $5.5 \%$. Entre 2004 e 2014 a temperatura média da regiáo passou de $30.1^{\circ} \mathrm{C}$ para $28.4^{\circ} \mathrm{C}$, ou seja, abaixou em cerca de $1.7^{\circ} \mathrm{C}$. Após análise das imagens coletadas, foi constatado que ao longo dos anos houve algum crescimento da área construída, cerca de $6.2 \%$ e também a pavimentação de algumas vias da região, o que aumentou em $5.2 \%$ a área asfaltada, no entanto, observou-se também um aumento significativo da área arborizada e de vegetaçáo densa, cerca de $14,2 \%$.

A Figura 5 mostra a caracterização dos revestimentos no ponto B nos anos estudados, enquanto o gráfico apresentado na Figura 6 expóe em porcentagem o quanto a área coberta por cada tipo de revestimento variou em 10 anos e também a variaçáo em porcentagem da temperatura no ponto no período considerado. 
Figura 5: Caracterizaçáo dos revestimentos do ponto B

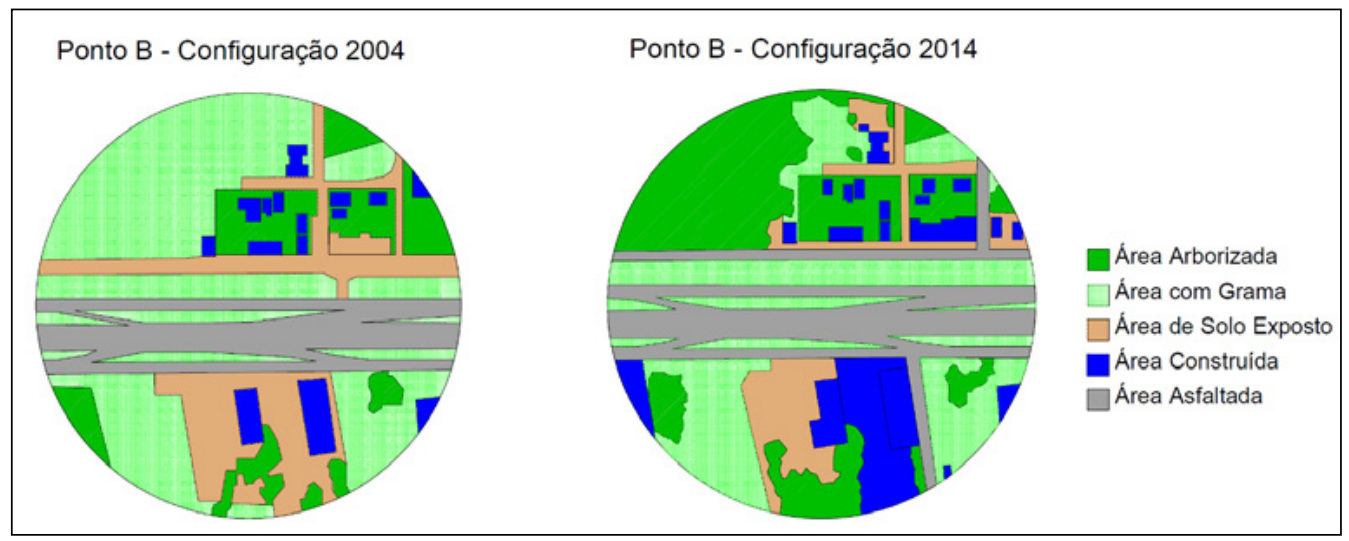

Fonte: dos autores.

Figura 6: Gráfico contendo a variação da temperatura no ponto $\mathrm{B}$ e as respectivas variaçóes em porcentagem das áreas por tipo de revestimento do solo

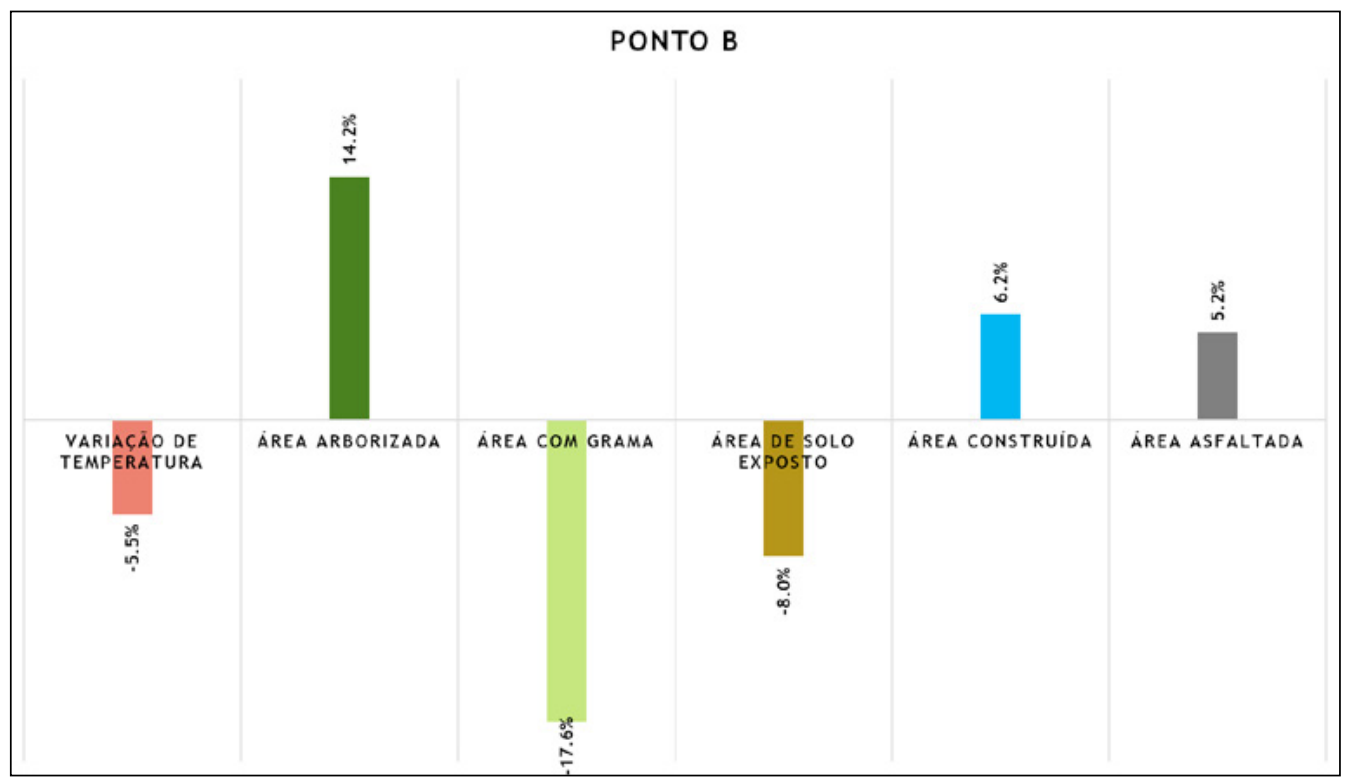

Fonte: dos autores. 


\subsection{Ponto C}

Assim como o ponto B, o ponto $\mathrm{C}$ também foi locado na avenida Fernando Corrêa, porém seus arredores são de área um pouco mais urbanizada com considerável tráfego de veículos pois esta via funciona como ligação dos bairros periféricos ao centro de Cuiabá. A análise deste ponto também apresentou resultados favoráveis ao conforto térmico do local. Ao longo dos dez anos de acompanhamento a temperatura diminui $1.6^{\circ} \mathrm{C}$ no ponto $\mathrm{C}$, ou seja, houve uma variação de $-5,4 \%$ na temperatura média anual. No gráfico da Figura 8 , observa-se que com relação aos revestimentos houve um aumento significativo da área verde arborizada e da área construída, respectivamente $27 \%$ e $12.6 \%$, enquanto que as áreas de solo exposto diminuíram em $16.9 \%$ e as áreas cobertas apenas com grama apresentaram variação negativa de $24.6 \%$ conforme Figura 7 e 8.

Figura 7: Caracterizaçáo dos revestimentos do ponto C

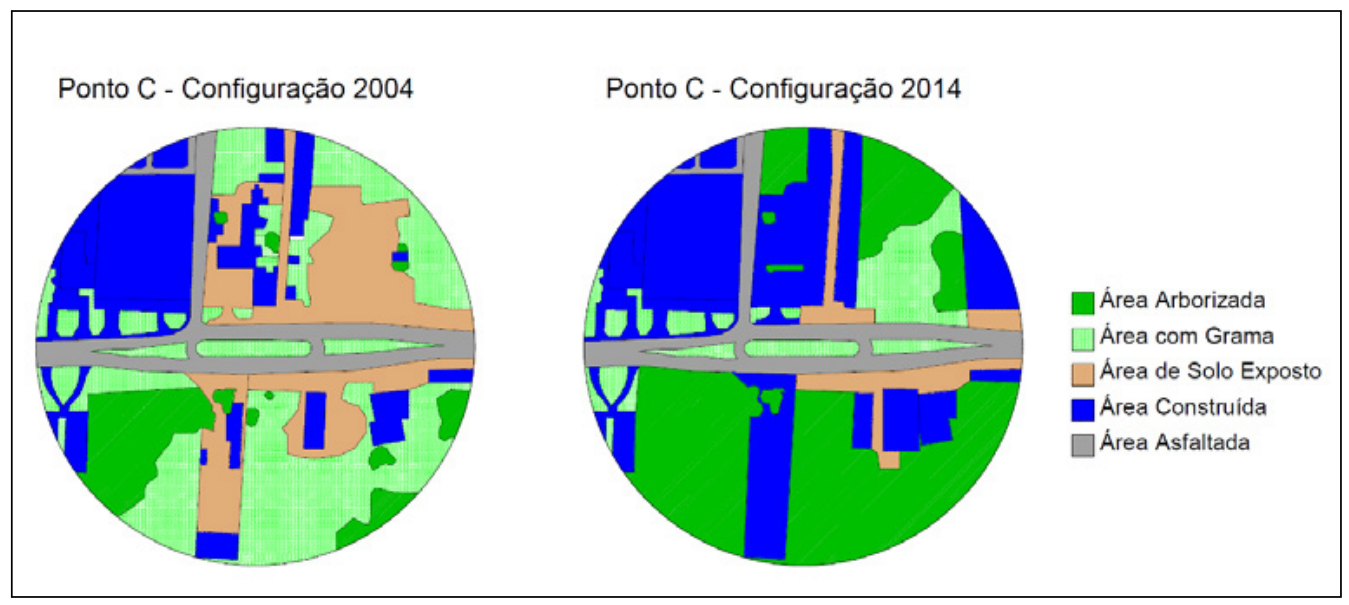

Fonte: dos autores. 
Figura 8: Gráfico contendo a variação da temperatura no ponto $\mathrm{C}$ e as respectivas variaçóes em porcentagem das áreas por tipo de revestimento do solo

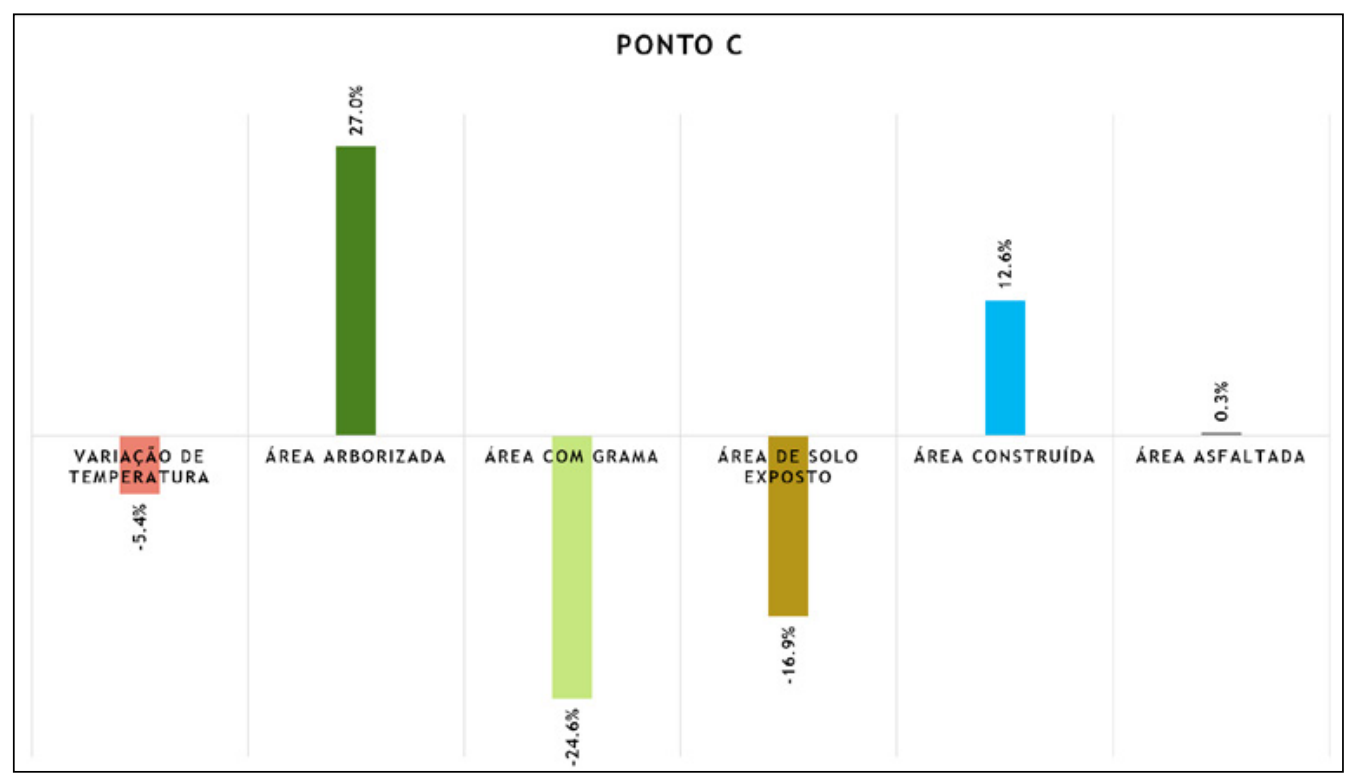

Fonte: dos autores.

\subsection{Ponto E}

O ponto E foi localizado na Avenida Fernando Corrêa próximo a entrada do campus da Universidade Federal de Mato Grosso - UFMT e a próximo ao shopping 3 Américas. Dentre os quatro pontos estudados este foi o que apresentou o maior aumento de temperatura, $2 \%$ acompanhado por um aumento das áreas construída, asfaltada e de solo exposto e diminuição da área verde.

Observou-se, pelas Figuras 9 e 10, que no ano de 2004 havia uma grande concentração de espécies arbóreas no campus da UFMT, e que parte dessa reserva verde teve que ser removida para a implantaçáo e duplicaçáo da futura Avenida Parque do Barbado, além disso, também houve a construçáo do viaduto da UFMT como parte do pacote de obras da copa de 2014, o que contribui para os resultados de variaçáo dos tipos de revestimentos do solo de variação percentual de temperatura apresentados pelo ponto E. 
Figura 9: Caracterização dos revestimentos do ponto E

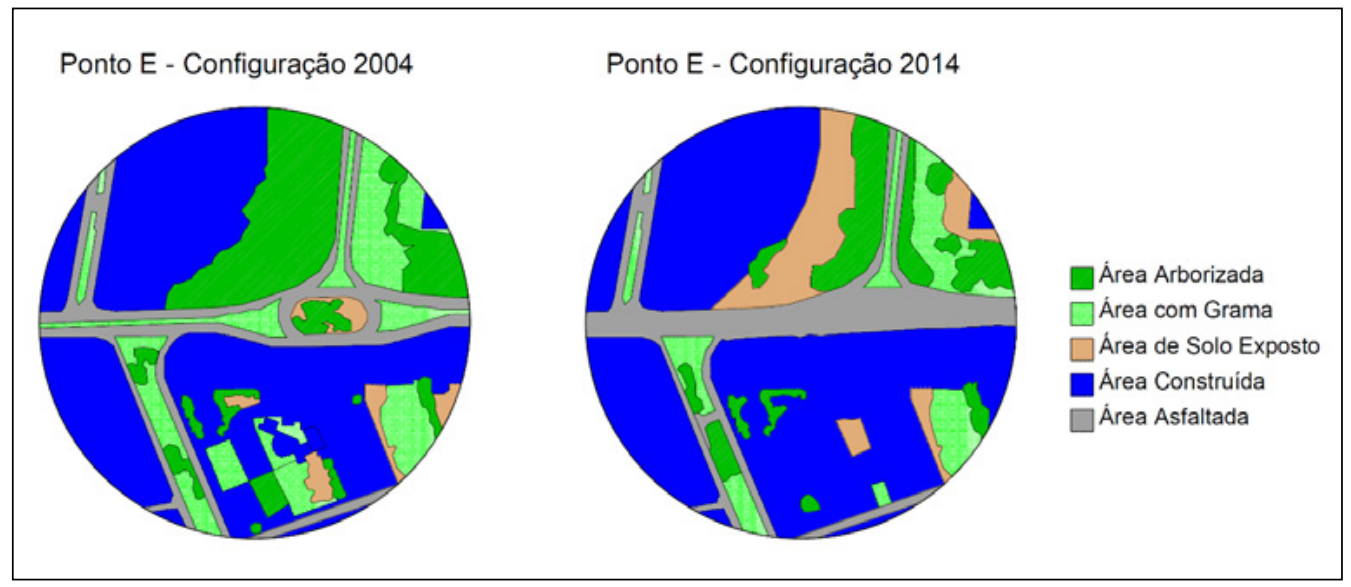

Fonte: dos autores.

Figura 10: Gráfico contendo a variação da temperatura no ponto E e as respectivas variaçóes em porcentagem das áreas por tipo de revestimento do solo

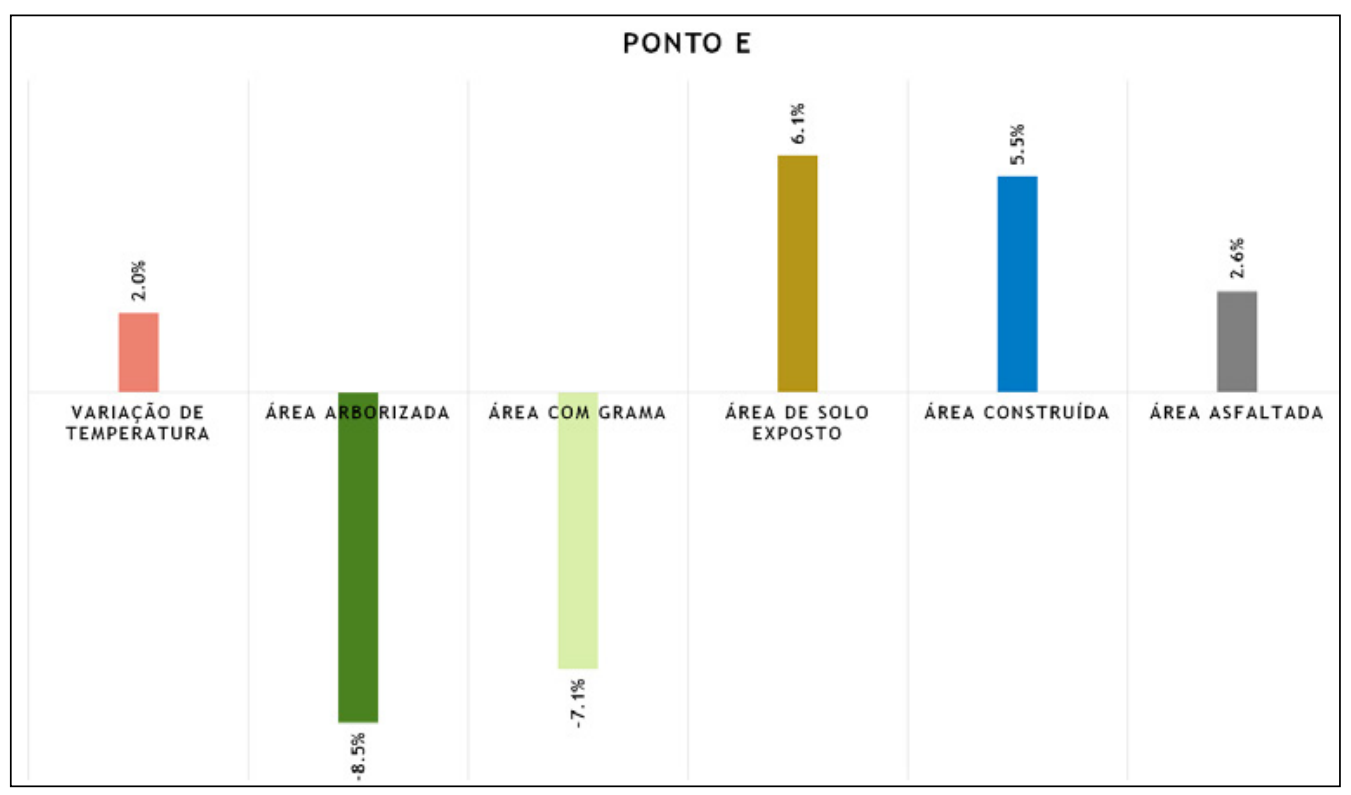

Fonte: dos autores.

\subsection{Ponto $\mathrm{H}$}

$\mathrm{O}$ quarto ponto cujos dados foram analisados foi o ponto $\mathrm{H}$, pois apresentou a segunda maior alta de temperatura, aproximadamente $1,7 \%$ comparado ao ano de 2004 , quando apresentou temperatura média anual de $28.7^{\circ} \mathrm{C}$. O ponto foi locado na Av. 
Tenente Coronel Duarte próximo ao supermercado Atacadão e ao Shopping popular, área essencialmente comercial possuindo vias asfaltadas e de intenso tráfego durante o horário comercial. Como é possível observar nas Figuras 11 e 12, entre os anos de 2004 e 2014 a região recebeu algumas obras de reestruturação, ocorrendo a incorporação de uma via ao terreno do supermercado Atacadáo, o que acarretou em uma diminuição da porcentagem de solo coberto por asfalto. Devido as obras no ano de 2014, a análise dos dados mostrou um aumento significativo na porcentagem de solo exposto, cerca de $25 \%$, enquanto as áreas verdes e construídas também diminuíram.

Figura 11: Caracterização dos revestimentos do ponto $\mathrm{H}$

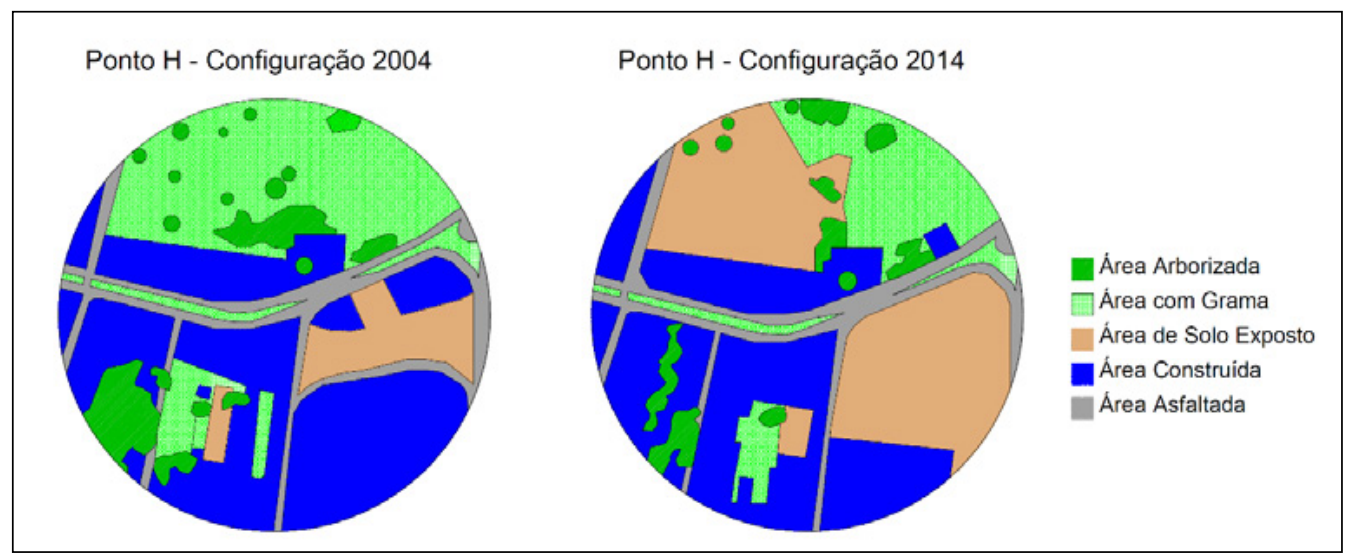

Fonte: dos autores. 
Figura 12: Gráfico contendo a variação da temperatura no ponto $\mathrm{H}$ e as respectivas variaçóes em porcentagem das áreas por tipo de revestimento do solo

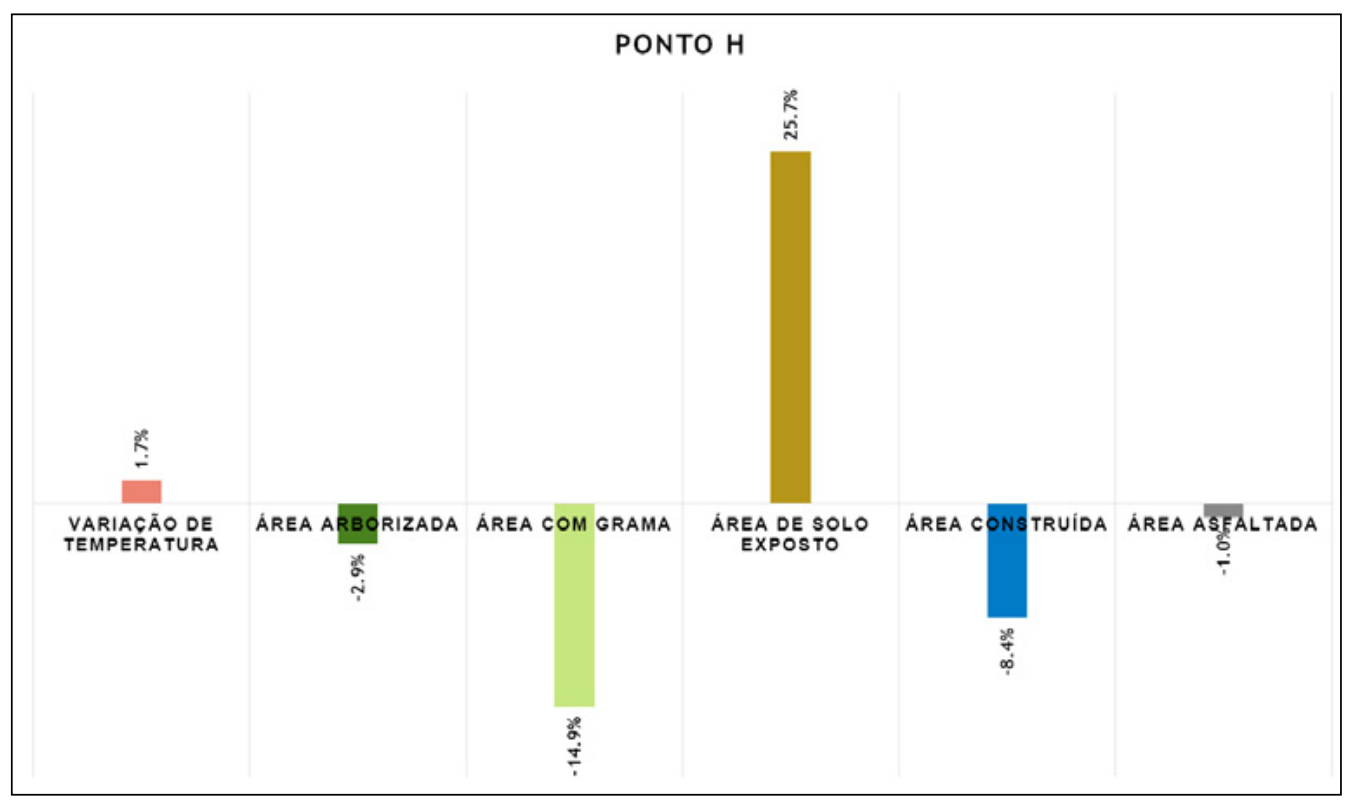

Fonte: dos autores.

\section{ANALISE GERAL DOS RESULTADOS}

A partir da análise de dados observou-se que os pontos que tiveram variação negativa de temperatura apresentaram resultados positivos quanto ao aumento de área arborizada, mesmo tendo apresentado crescimento das áreas construídas ou asfaltadas; no entanto, a variação positiva da área arborizada foi significantemente maior que as demais. Os pontos que apresentaram aumento de temperatura, apresentaram conjunto variação positiva da área construída, asfalta e/ou solo expostos, e um decréscimo da área arborizada e gramínea, ou seja, a área verde foi substituída pelos demais revestimentos. Com isso podemos concluir que um aumento de área arborizada nas cidades contribui de maneira positiva ao conforto térmico da cidade, repercutindo diretamente na diminuiçẫo de temperaturas.

Em estudo semelhante, Freitas, Santos e Amorim (2014) chegaram a resultados parecidos com os resultados desta pesquisa, após estudar a variação de temperatura de diferentes pontos, cada qual com um tipo de revestimento, assim como nesta pesquisa, Freitas, Santos e Amorim também observaram que em locais próximos a vegetação as médias de temperatura são menores.

Nince et al. (2014), estudando a variaçáo de temperatura em diversos pontos dentro da na Universidade Federal de Mato Grosso, em Cuiabá, chegaram à conclusão de que o sombreamento arbóreo e a superfície gramínea, por apresentarem menores temperaturas máximas, propiciam maior conforto térmico quando comparado a superfícies revestidas por concreto e asfalto (FIGURA 13). 
Figura 13: Dados de variação de temperatura e tipos de revestimento agrupados

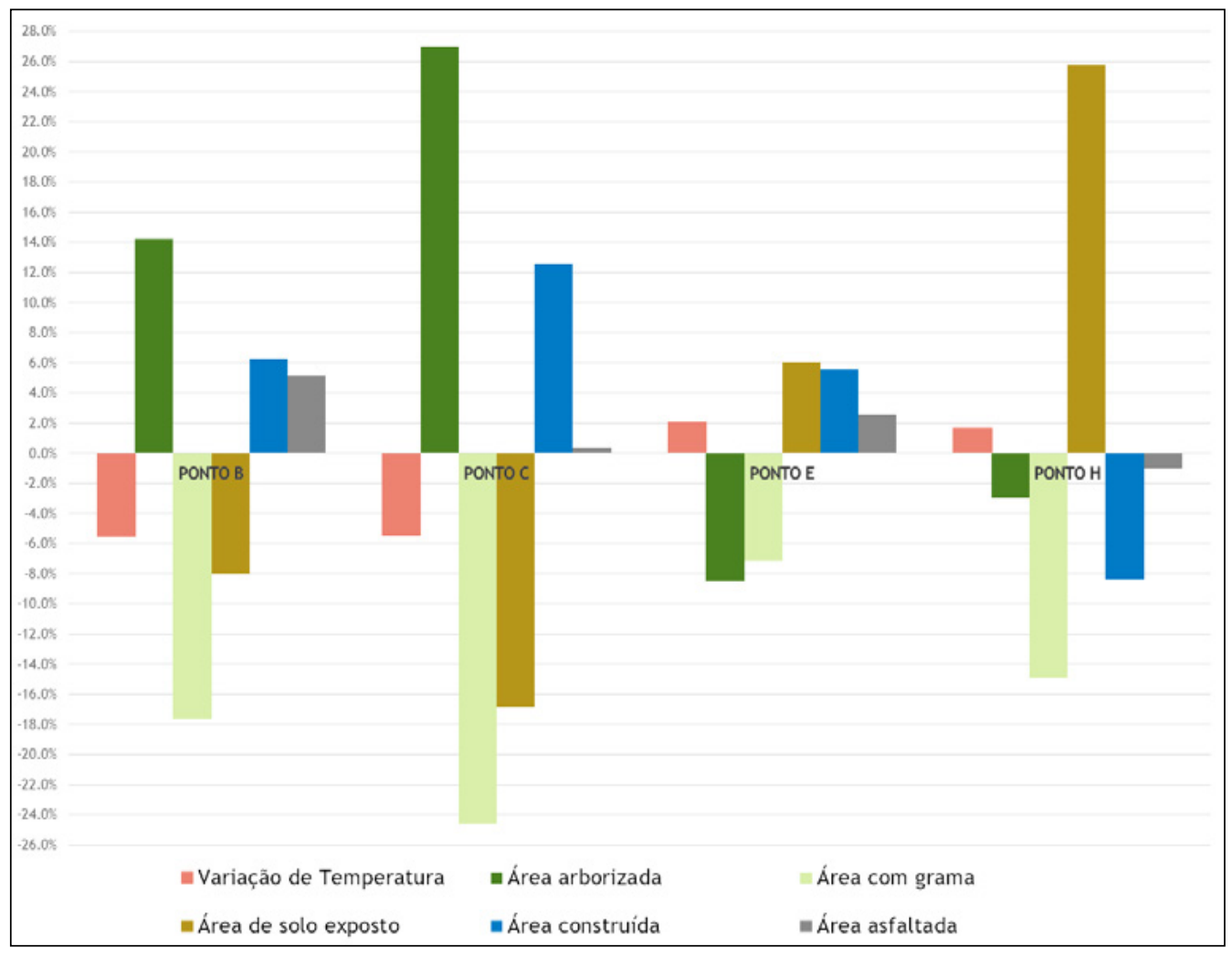

Fonte: dos autores.

\section{CONSIDERAÇÓES FINAIS}

O calor excessivo é uma das principais causas de desconforto térmico no meio urbano. O resultado deste estudo reafirma o que já é conhecido por muitos, áreas arborizadas exercem papel preponderante no que diz respeito ao conforto térmico ambiental, atuando como reguladora do campo térmico urbano além de fornecer sombreamento em áreas abertas.

Com a urbanização as cidades estão crescendo inconscientemente, sem nenhum tipo de prática preventiva quanto ao conforto dos seus habitantes, com isso a populaçáo tem recorrido a formas artificiais de resfriamento, consumindo mais energia e gerando mais impacto ambiental. Visando o conforto dos seus habitantes e uma maior responsabilidade social, a prática da arborização deveria ser uma constante no planejamento e manutenção das cidades. 


\section{Referências:}

CUIABA, Prefeitura Municipal; Instituto de Pesquisas e Desenvolvimento Urbano IPDU. Diretoria Estadual de Pesquisa e Informação. Perfil Socioeconômico de Cuiabá, Cuiabá, v. IV, 2009.

FRANCO, Fernanda Miguel. Análise do comportamento termo-higrométrico urbano sob a ótica do uso e ocupação do solo em Cuiabá - MT. Cuiabá, 2013. 142f. Tese (Mestrado) - Programa de Pós-Graduação em Física e Meio Ambiente, UFMT, 2013.

FREITAS, Anne; SANTOS, Joel; ALMEIDA, Nadjacleia. Avaliação do conforto térmico do campus IV - Rio Tinto aplicado ao ordenamento territorial ambiental. Caminhos da Geografia, Uberlândia, v. 15, n. 50, p. 89-99, Jun. 2014.

GOMES, Marcos A. S.; AMORIM, Margarete C. C. T. Arborização e conforto térmico no espaço urbano: estudo de caso nas praças públicas de Presidente Prudente (SP).

Caminhos da Geografia, Uberlândia, v. 07, n. 10, p. 94-106, Set. 2003.

NINCE et al. Conforto térmico dos usuários em vegetação e revestimento urbanos no campus da UFMT em Cuiabá - MT. Remoa, Santa Maria, v. 13, n.4, p.3529-3541, SetDez. 2014.

SAMPAIO, Mariza de Mello Arruda. Análise do desempenho térmico e lumínico de habitaçóes populares em Cuiabá - MT. Cuiabá, 2006. 123f. Tese (Mestrado) Programa de Pós-Graduação em Física e Meio Ambiente, UFMT, 2006.

SAMPAIO, Mariza de Mello Arruda. Transformaçóes microclimáticas e legislação: o caso de Cuiabá-MT. Rio de Janeiro, 2015. 227f. Tese (Doutorado) - Faculdade de PósGraduação em Urbanismo, UFRJ, 2015.

SILVEIRA, Lucia R. C. da; ROMERO, Marta A. B. Indicadores de sustentabilidade urbana. In: ENCONTRO NACIONAL DA ASSOCIAÇÃO NACIONAL DE PÓSGRADUAÇÃO E PESQUISA EM PLANEJAMENTO URBANO E REGIONAL, XI, 2005, Salvador. Anais... Belo Horizonte: Associação Nacional de Pós-Graduação e Pesquisa, 2005.

SOUZA, Débora M. de; NERY, Jonas T. O conforto térmico na perspectiva da Climatologia Geográfica. Geografia, Londrina, v. 21, n. 02, p. 65-83, maio/ago. 2012.

VILLAR FILHO, O. C.; ARAÚJO, V. M. D.; COSTA, A. D. L. Estudos microclimáticos de revestimentos das estruturas viárias em uma fração urbana de João Pessoa-PB.

Paranoá, Brasília, no 11, p. 35-44, 2014. Encontro Nacional de Conforto no Ambiente Construído, 12; Encontro Latinoamericano de Conforto no Ambiente Construído, 8, 2013, Brasília. 